\title{
Induction reflex actions with intravenous nalbuphine as an adjunct to isoflurane
}

Ninety unpremedicated patients undergoing mask anaesthesia were assigned to one of three groups according to the volatile anaesthetic and the acute intravenous premedication adminis. tered. Group I received saline placebo as premedication and haiothane by inhalation. Group II received saline placebo and isoflurane by inhalation. Group III received nalbuphine $0.1 \mathrm{mg} \cdot \mathrm{kg}^{-1} \mathrm{IV}$ as premedication and isoflurane by inhalation. Mean time to loss of consciousness ( $71 \mathrm{sec}$ ) did not differ among groups. The dosage of thiopentone required to induce loss of consciousness was decreased by 15 per cent (from 3.9 to $\left.3.3 \mathrm{mg} \cdot \mathrm{kg}^{-1}\right)$ by nalbuphine premedication $(P<0.05$ ), and time to induction of surgical anaesthesia using isofturane was decreased by 15 per cent $(P<0.05)$. The incidence of reflex actions (coughing, laryngospasm, breath holding, hiccoughs and movement) during induction was no different in the saline-premedicated halothane or isoflurane groups. Acute intravenous nalbuphine premedication decreased significantly the incidence of reflex actions during induction of isoflurane anaesthesia from 77 per cent to 37 per cent $(P<0.02)$. Desaturation episodes $\left(\mathrm{SaO}_{2}<90\right.$ per cent $)$ were more frequent with isoflurane inductions compared with halothane (55 per cent us 17 per cent, $P<0.01$ ). Apnoeic episodes accounted for the majority of desaturations associated with nalbuphine premedication, while excitatory reflexes (coughing and laryngospasm) accounted for more desaturations with isoflurane alone.

\section{Key words}

ANAESTHETIC TECHNIQUES: inhalation; ANAESTHETICS, VOLATILE: isoflurane, halothane; ANALGESICS: nalbuphine.

From the Department of Anaesthesia, Mount Sinai Hospital, University of Toronto, 600 University Avenue, Toronto, Ontario, M5G 1X5 Canada

Address correspondence to: Dr. Mallon.

This study was supported by a Medical Research Council of Canada summer scholarship.
The tendency of isoflurane anaesthesia to provoke unwanted reflex actions such as coughing, laryngospasm and breath-holding has been well documented. ${ }^{1-4}$ These reflex actions are most common during induction ${ }^{1,5}$ of anaesthesia and are more common and/or more severe when compared with halothane $e^{5-8}$ and enflurane..$^{5}$

Several investigators have suggested that the use of preinduction narcotics with isoflurane anaesthesia decreased the incidence and severity of reflex actions. ${ }^{1-3}$ Their studies were either retrospective or uncontrolled, and included both intubated and non-intubated patients. No prospective blinded studies have investigated the effect of IV adjuncts on reflex action suppression during mask anaesthesia with isoflurane.

Nalbupine is a partial opioid agonist-antagonist, structurally related to oxymorphone and to naloxone. Its analgesic potency is equal to morphine in doses of $10 \mathrm{mg} \cdot 70 \mathrm{~kg}^{-1}$ or less, however higher doses exhibit a ceiling effect on respiratory depression. ${ }^{9}$ Previous studies have demonstrated that nalbuphine premedication reduced excitatory phenomena during mask anaesthesia with althesin, ${ }^{10}$ methohexitone-nitrous oxide, ${ }^{11}$ and halothane-nitrous oxide. ${ }^{12}$

This study was designed to compare the incidence of reflex actions during induction of surgical anaesthesia by mask using halothane and isoflurane, and to determine the effect of acute IV premedication with nalbuphine on reflex actions during induction with isoflurane.

\section{Methods}

The study protocol was approved by the the University of Toronto Human Subjects Review Committee, and informed consent was obtained. Ninety unpremedicated in-patients scheduled for minor elective surgery for which mask anaesthesia was deemed appropriate were studied. All were ASA physical status I or II, of either sex, and between 16 and 70 years of age. Grounds for exclusion included morbid obesity, hiatus hernia, and lack of dentition. Asymptomatic smokers were not excluded.

Patients were allocated by draw to one of three equal 
groups whose anaesthetic management differed only in the choice of IV premedicant and volatile agent. Group I (halothane) received a placebo premedicant of normal saline $0.05 \mathrm{ml} \cdot \mathrm{kg}^{-1}$, and halothane by inhalation. Group II (isoflurane) received the same placebo premedicant, but inhaled isoflurane. Group III (nalbuphine/isoflurane) received IV nalbuphine diluted to $2 \mathrm{mg} \cdot \mathrm{ml}^{-1}$ in saline, in a dose of $0.05 \mathrm{ml} \cdot \mathrm{kg}^{-1}$ (nalbuphine $0.1 \mathrm{mg} \cdot \mathrm{kg}^{-1}$ ) as premedicant, and inhaled isoflurane.

All patients were anaesthetized according to the following protocol by the author (JSM), who was blinded both to the premedicant and to the volatile agent administered. Halothane and isoflurane were administered (in 0.5 per cent increments) from newly calibrated Fortec and Fluotec vaporizers (Cyprane) which were visually indistinguishable to the anaesthetist.

Induction protocal: patients were neither preoxygenated nor instructed as to breathing during the induction of anaesthesia. Three minutes after receiving the IV premedicant unconsciousness was induced with thiopentone IV $2.5 \mathrm{mg} \cdot \mathrm{kg}^{-1}$ as a bolus, followed by $50-75 \mathrm{mg}$ increments titrated to loss of eye-opening on verbal command. A tight-fitting mask was then applied, and spontaneous ventilation of nitrous oxide ( 60 per cent) and oxygen $\left(6+4 \mathrm{~L} \cdot \mathrm{min}^{-1}\right.$ respectively) from a co-axial circuit was permitted. Manual ventilation was avoided unless apnoea persisted longer than 60 seconds or arterial oxygen saturation fell below 90 per cent. The volatile agent was introduced in increments of 0.5 per cent after every third breath, in the absence of coughing, laryngospasm or breath-holding, to a maximum of 3.0 per cent. The induction period was considered over when the patient was judged to be surgically anaesthetized by the anaesthetist according to traditional signs of cardiac and respiratory stability, conjugate gaze, and lack of response to insertion of an oral airway.

Data collection: all data was collected by the same observer (CB), who was similarly blinded to the anaesthetic regimen. Demographic data included age, sex, height and weight, and smoking history. The body mass index (BMI) was calculated as weight $(\mathrm{kg}) \div$ height $^{2}\left(\mathrm{~m}^{2}\right)$. Monitors included an ECG, automatic blood pressure cuff with printout, and a pulse oximeter (Biox II) with continuous printout of arterial oxygen saturation. Baseline vital signs and oxygen saturations were recorded before and after the administration of the premedicant.

Induction data recorded included the total sleep dose of thiopentone, the time to loss of consciousness (from start of thiopentone injection to mask application), the continuous oxygen saturation, and the total induction time (from the start of thiopentone injection to the uneventful insertion of an oral airway). Following loss of consciousness, every spontaneous and/or manual breath was ob- served and recorded on the oximeter printout. Similarly, any induction phenomena such as cough, laryngospasm, movement, phonation, breath holding or hiccough was recorded. From the oximeter printout the incidence, duration and degree of any desaturation below 90 per cent, and the respiratory rate during the final $\mathbf{3 0}$ seconds of the induction period before oral airway insertion were calculated.

Within five minutes of the onset of surgical stimulation, under conditions of stable respiration, an "arterialized" venous blood sample was drawn from the dorsum of the hand or forearm and analysed for blood gases.

Following surgical stimulation, the inspired concentration of the volatile agent was lowered in 0.5 per cent decrements to the lowest value consistent with stable surgical anaesthesia, and this maintenance value was recorded.

Statistical analysis: between-group comparisons of demographic variables were analyzed by a one-way analysis of variance. All other data presented as means $\pm S D$ were analyzed by non-parametric methods (Kruskal-Wallis and Mann-Whitney rank sum tests with Bonferroni adjustment for multiple comparisons). Between-group differences in proportions were analysed by a chi-squared test with Yates' continuity correction and Bonferroni adjustment. Statistical significance was accepted for $P<0.05$.

\section{Results}

Analysis of demographic data revealed no significant differences among groups with respect to mean age, height, weight, BMI, sex distribution or proportion of smokers ( 32 per cent overall).

Three patients, one from each group, developed intractable laryngospasm during induction of anaesthesia necessitating abandonment of the protocol and tracheal intubation following IV succinylcholine. These failed inductions were without clinically important sequelae.

There was no difference in the mean time to loss of consciousness among groups (Table I). The mean sleep dose of thiopentone required was decreased by nalbuphine premedication by about 15 per cent. The mean total induction time to surgical anaesthesia was longer for isoflurane without nalbuphine compared with both other groups.

Table II outlines the incidence of events at induction of anaesthesia. Reflex actions were equally common in the placebo-premedicated halothane and isoflurane groups, with an 80 per cent overall incidence of onc or more unwanted reflexes. Nalbuphine premedication significantly decreased the overall incidence of reflex actions (one or more) to $11 / 30$ or 37 per cent $(P<0.02)$. In 
Table 1 Induction results (mean $\pm \mathrm{SD}$ )

\begin{tabular}{llll}
\hline & \multicolumn{2}{l}{ Group } & \\
\cline { 2 - 4 } & $\begin{array}{l}l \\
\text { (hal) }\end{array}$ & $\begin{array}{l}\text { II } \\
\text { (iso) }\end{array}$ & $\begin{array}{l}\text { III } \\
\text { (nal-iso) }\end{array}$ \\
\hline $\begin{array}{l}\text { n(1) } \\
\begin{array}{l}\text { Time to loss } \\
\text { of consciousness (sec) }\end{array}\end{array}$ & $74 \pm 25$ & $73 \pm 19$ & $66 \pm 19$ \\
$\begin{array}{l}\text { Total induction } \\
\text { time (sec) }\end{array}$ & $275 \pm 58$ & $318 \pm 96^{*}$ & $270 \pm 70$ \\
$\begin{array}{l}\text { Sleep dose of } \\
\text { thiopentone }\left(\mathrm{mg} \cdot \mathrm{kg}^{-1} \text { ) }\right.\end{array}$ & $3.9 \pm 1.3$ & $3.9 \pm 1.1$ & $3.3 \pm 1.2 \dagger$ \\
\hline
\end{tabular}

(1) $\mathbf{n}=29 ; 1$ failed induction excluded in each group.

*P $<0.05$ II vs I + III.

$+\mathrm{P}<0.05$ III vs I + II

particular, the incidence of coughing ( $P<0.003$ ) was markedly reduced by nalbuphine premedication.

Except for the isolated occurrence of hiccoughs in one Group III patient, the lowest incidence of each specific reflex action was found in the nalbuphine premedicated group.

No desaturation episodes $\left(\mathrm{SaO}_{2}<90\right.$ per cent) occurred following the administration of nalbuphine but prior to induction of anaesthesia. Following thiopentone, such episodes were significantly more frequent in both isoflurane groups (55 per cent overall incidence) compared with the halothane group ( 17 per cent $P<0.01$ ). The three profound desaturations $\left(\mathrm{SaO}_{2}<75\right.$ per cent) were all associated with laryngospasm and a failed induction. Correlates of desaturation during isoflurane

Table II Incidence of induction events

\begin{tabular}{|c|c|c|c|}
\hline & \multicolumn{3}{|c|}{ Group } \\
\hline & $\begin{array}{l}\text { (hal) } \\
\text { (hat) }\end{array}$ & $\begin{array}{l}\| \\
\text { (iso) }\end{array}$ & $\begin{array}{l}\text { II } \\
\text { (nat-iso) }\end{array}$ \\
\hline n & 30 & 30 & 30 \\
\hline \multicolumn{4}{|l|}{ Reflex actions } \\
\hline - None & 5 & 7 & $19 *$ \\
\hline - Cough & 18 & 12 & $3 t$ \\
\hline - Laryngospasm & 1 & 6 & I \\
\hline - Movement & 12 & 17 & 8 \\
\hline - Breath holding & 12 & 14 & 8 \\
\hline - Phonation & 6 & 7 & 2 \\
\hline - Hiccough & 0 & 0 & 1 \\
\hline \multicolumn{4}{|l|}{ Desaturation } \\
\hline$-\mathrm{SaO}_{2}<90 \%$ & $5 \ddagger$ & 13 & 20 \\
\hline$-\mathrm{SaO}_{2}<75 \%$ & 1 & 1 & 1 \\
\hline \multicolumn{4}{|l|}{ Manual ventilation } \\
\hline needed & 2 & 3 & 9 9ु \\
\hline
\end{tabular}

$* \mathrm{P}<0.02$, III vs I + II.

tP $<0.01$, III vs I + II.

$\$ \mathrm{P}<0.01, \mathrm{I}$ vs II + III.

$8 \mathrm{P}<0.05$, III vs I + II.
Table III End-induction respiratory rate and blood gases (mean \pm SD)

\begin{tabular}{|c|c|c|c|}
\hline & \multicolumn{3}{|l|}{ Group } \\
\hline & $\begin{array}{l}l \\
\text { (hal) }\end{array}$ & $\begin{array}{l}I \\
\text { (iso) }\end{array}$ & $\begin{array}{l}\text { III } \\
\text { (nal-iso) }\end{array}$ \\
\hline n & 29 & 29 & 29 \\
\hline $\begin{array}{l}\text { Respiratory rate } \\
\left(\min ^{-1}\right) \\
\text { "Arterialized" venous } \\
\text { blood gases }\end{array}$ & $24 \pm 8$ & $22 \pm 6$ & $14 \pm 5^{*}$ \\
\hline $\begin{aligned}- & \mathrm{pH} \\
- & \mathrm{PCO}_{2}(\mathrm{kPa}) \\
& (\mathrm{mmHg})\end{aligned}$ & $\begin{array}{l}7.37 \pm 0.03 \\
5.73 \pm 0.67 \\
43.1 \pm 5.0\end{array}$ & $\begin{array}{l}7.37 \pm 0.04 \\
5.87 \pm 0.86 \\
44.1 \pm 6.5\end{array}$ & $\begin{array}{l}7.35 \pm 0.04 \\
6.06 \pm 0.76 \\
45.6 \pm 5.7\end{array}$ \\
\hline
\end{tabular}

$* \mathrm{P}<0.005$, III vs I + II.

inductions appeared to vary according to the premedicant. Excluding the one failed induction, no desaturation in the nalbuphine-premedicated group was associated with coughing or laryngospasm; the commonest association was with apnoea following loss of consciousness in 13/20 (65 per cent) of cases. This contrasted with the nonpremedicated isoflurane patients were desaturations were associated with cough or laryngospasm in $5 / 13$ (38 per cent) of cases, and with apnoea in only $4 / 13$ ( 31 per cent). Desaturation following loss of consciousness but not associated with apnoea or reflex respiratory excitement occurred in all three groups with an overall incidence of 9/38 (24 per cent): such episodes were generally brief, mild and self-limited. All desaturations responded to corrective measures.

A higher incidence of requirement for manual ventilation for apnoea and/or desaturation following nalbuphine was noted ( 30 per cent vs 8 per cent, $P<0.05$ ). The end-induction respiratory rate was likewise significantly lower following nalbuphine premedication by about 36 per cent $(P<0.005$ ). Despite this reduction, the "arterialized" venous $\mathrm{PCO}_{2}$ showed no difference among groups following surgical stimulation.

Nalbuphine premedication lowered the maintenance requirement for isoflurane. Following nalbuphine, 66 per cent (19/29) of patients were able to be maintained on 0.5 per cent inspired isoflurane, whereas 76 per cent $(22 / 29)$ of patients receiving placebo required $1.0-1.5$ per cent inspired isoflurane $(P<0.05)$.

\section{Discussion}

Strategies suggested to minimize unwanted reflex actions during isoflurane anaesthesia have included the concomitant use of narcotic and anticholinergic premedication, 1,3 the use of barbiturates ${ }^{1,3}$ and nitrous oxide ${ }^{2,3}$ during induction of anaesthesia, and limiting inspired isoflurane concentrations to 2.5 per cent or less. ${ }^{1}$ Most, if not all, of 
these recommendations are based on uncontrolled retrospective studies. Our intention was to determine in a blinded, prospective fashion, whether the pre-induction administration of a small dose of IV narcotic would "smooth out" a thiopentone-isoflurane-nitrous oxide mask anaesthetic induction without unacceptable respiratory depression.

Intravenous nalbuphine did not accelerate the onset of loss of consciousness, but did decrease the sleep dose of thiopentone required. Like others, ${ }^{11,13}$ we found that nalbuphine reduced thiopentone requirements by about 15 per cent, an amount of minimal clinical importance.

Despite what might be expected on the basis of solubility, we found that total induction time was greater with isoflurane alone than with halothane, by about 16 per cent. Other investigations have reported similar findings, ${ }^{5,6,8}$ and attribute the delayed induction with isoflurane to an increased incidence of breath holding, coughing and laryngospasm. This explanation is supported by our finding that the addition of nalbuphine premedication obviated the increase in induction time, while significantly decreasing the incidence of reflex actions overall, and in particular cough.

Surprisingly we were unable to detect any difference in incidence of reflex actions between halothane and isoflurane without premedication. Since we introduced halothane and isoflurane "as tolerated" rather than in equivalent MAC-multiple rates, halothane was probably introduced at a higher MAC-equivalent rate than was isoflurane. This may have accounted for the similar reflex action incidence, and for the longer induction time with isoflurane. Isoflurane was associated with a marked increase in desaturation episodes; however, the aetiology appeared to differ according to the premedication. A placeboassociated desaturation was more likely to follow an excitatory respiratory reflex such as coughing or laryngospasm, whereas a nalbuphine-associated desaturation was more commonly accompanied by respiratory depression and apnoea. In general, apnoea-associated desaturations were brief, well-tolerated, and more easily reversed compared with reflex-associated desaturations. Despite a marked reduction in respiratory rate at end-induction following nalbuphine premedication, no significant differences in arterialized venous $\mathrm{PCO}_{2}$ were found among groups following surgical stimulation.

A surprising incidental finding in all groups was the relatively high incidence of oxygen desaturation associated with loss of consciousness alone but not with apnoea or excitatory reflexes. These episodes were brief and of minimal clinical importance in this otherwise healthy population. Whether pre-oxygenation would prove of benefit in prevention of these desaturations remains conjectural.
In summary, we conclude that a small dose of intravenous nalbuphine administered prior to induction of anaesthesia decreases the incidence of excitatory induction phenomena associated with isoflurane mask anaesthesia, but may increase the incidence of apnoeic episodes and subsequent arterial oxygen desaturation.

\section{References}

1 Buffington $C W$. Reflex actions during isoflurane anaesthesia. Can Anaesth Soc J 1982; 29: S35-43.

2 Pauca AL, Dripps RD. Clinical experience with isoflurane (Forane*). Br J Anaesth 1973; 45: 697-703.

3 Homi J, Konchigeri $H N$, Eckenhoff JE, Linde HW. A new anesthetic agent-Forane. Preliminary observations in man. Anesth Analg 1972; 51:439-47.

4 Wren WS, McShane AJ, MCCarthy JG, Lamont BJ, Casey $W F$, Hamnon VM. Isoflurane in paediatric anaesthesia. Anaesthesia 1985; 40: 315-23.

5 Fisher DM, Robinson S, Brett CM, Perin G, Gregory $G A$. Comparison of enflurane, halothane and isoflurane for diagnostic and therapeutic procedures in children with malignancies. Anesthesiology 1985; 63: 647-50.

6 Cantermole RW, Verghese C, Blair IJ, Jones CJH, Flynn $P J$, Sebel PS. Isoflurane and halothane for outpatient dental anaesthesia in children. Br J Anaesth 1986; 58: 385-9.

7 McAteer PM, Carter JA, Cooper GM, Prys-Roberts C. Comparison of isoflurane and halothane in outpatient paediatric dental anaesthesia. $\mathrm{Br} \mathrm{J}$ Anaesth 1986; 58: 390-3.

8 Kingston HGG. Halothane and isoflurane in pediatric outpatients. Anesth Analg 1986; 65: 181-4.

9 Romagnoli A, Keats AS. Ceiling effect for respiratory depression by nalbuphine. Clin Pharmacol Ther 1980; 27: 478-85.

10 Kay $B$, Hargreaves $J$, Healy TEJ. Nalbuphine and Althesin* anaesthesia. Anaesthesia 1984; 39: 666-9.

11 Chestnutt WN, Clarke RSJ, Dundee JW. Comparison of nalbuphine, pethidine and placebo as premedication for minor gynaecological surgery. Br J Anaesth 1987; 59: 576-80.

12 Rita L, Seleny $F$, Goodarzi $M$. Comparison of the calming and sedative effects of nalbuphine and pentazocine for paediatric premedication. Can Anaesth Soc J 1980; 27: $546-9$.

13 Fragen RJ, Caldwell N. Acute intravenous premedication with nalbuphine. Anesth Analg 1977; 56: 808-12. 


\section{Résumé}

Nous avons séparé au hasard, 90 de nos patients devant avoir une anesthésie au masque en trois groupes. A chacun, nous injections d l'aveugle un composé intraveineux (C) trois minutes avant une dose d'induction de thiopental suivi d'un agent inhalatoire (I). " $C$ " et "I" respectivement, étaient pour le group I: placebo et halothane; group II: placebo et isoflurane; groupe III: nalbuphine $0.1 \mathrm{mg} \cdot \mathrm{kg}^{-1}$ et isoflurane. L'inconscience est survenue dans tous les groupes au même moment après l'injection de thiopental (71 sec. en moyenne) mais la dose nécessaire était réduite de 15 pour cent $\left(3.9\right.$ à $\left.3.3 \mathrm{mg} \cdot \mathrm{kg}^{-1}\right)$ par la nalbuphine $(P<0.05)$. Le temps nécessaire pour aneindre un plan d'anesthésie chirurgical était moindre de 15 pour cent avec $l$ 'isoflurane $(P<0.05)$. L'incidence de réflexes (toux, laryngospasme, apnée, hoquet et mouvement) était la même dans les groupes I et II. Cependant, avec la nalbuphine, l'incidence de réflexes à l' introduction de l' isoflurane passait de 77 pour cent d 37 pour cent $(P<0.02)$. Les épisodes de désaturation $\left(\mathrm{SaO}_{2}<90\right.$ pour cent) étaient plus fréquents avec l' isofurane qu'avecl' halothane 55 pour cent vs 17 pour cent, $P$ $<0.01)$. Ceste désaturation était surtout associée à de la toux ou d un laryngospasme avec l'isoflurane seul tandis qu'avec la nalbuphine, c'est surtout de l'apnée qui y contribuait. 